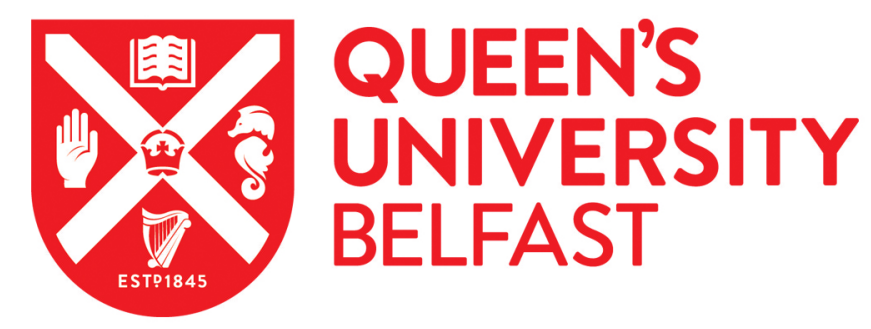

\title{
Purification and characterization of the major protein isolated from Semen Armeniacae Amarum and the properties of its thermally induced nanoparticles
}

Lin, D., Lin, W., Zhou, J., Chen, T., Ke, L., Rao, P., \& Wang, Q. (2020). Purification and characterization of the major protein isolated from Semen Armeniacae Amarum and the properties of its thermally induced

nanoparticles. International Journal of Biological Macromolecules. https://doi.org/10.1016/j.ijbiomac.2020.05.070

Published in:

International Journal of Biological Macromolecules

Document Version:

Peer reviewed version

Queen's University Belfast - Research Portal:

Link to publication record in Queen's University Belfast Research Portal

\section{General rights}

Copyright for the publications made accessible via the Queen's University Belfast Research Portal is retained by the author(s) and / or other copyright owners and it is a condition of accessing these publications that users recognise and abide by the legal requirements associated with these rights.

Take down policy

The Research Portal is Queen's institutional repository that provides access to Queen's research output. Every effort has been made to ensure that content in the Research Portal does not infringe any person's rights, or applicable UK laws. If you discover content in the

Research Portal that you believe breaches copyright or violates any law, please contact openaccess@qub.ac.uk. 


\section{Purification and characterization of the major protein isolated from Semen Armeniacae Amarum and the properties of its thermally induced nanoparticles}

Dai Lin ${ }^{\mathrm{a}, \mathrm{b}}$, Wei Lin ${ }^{\mathrm{c}}$, Guanzhen Gao ${ }^{\mathrm{a}}$, Jianwu Zhou ${ }^{\mathrm{a}} *$, Tianbao Chen ${ }^{\mathrm{d}}$, Lijing Ke ${ }^{\mathrm{a}}$, Pingfan Rao ${ }^{\mathrm{a}}$, Qiang Wang

${ }^{\text {a }}$ Food Nutrition Science Centre, School of Food Science and Biotechnology, Zhejiang Gongshang University, Hangzhou, Zhejiang, China

${ }^{\mathrm{b}}$ School of Public Health, Fujian Medical University, Fuzhou, Fujian, China

${ }^{\mathrm{c}}$ Institute of Biotechnology, Fuzhou University, Fuzhou, Fujian, China

${ }^{\mathrm{d}}$ Queen's University, Belfast, UK

${ }^{\mathrm{e}}$ Chinese Institute of Food Science and Technology, Chinese Academy of Agricultural Sciences, Beijing, China

*Corresponding author: Jianwu Zhou, Ph.D., jianwuzhou@zjgsu.edu.cn

*Corresponding author at: 1st Lab Building, Food Nutrition Center, Zhejiang Gongshang University, Hangzhou, China, 310012; Tel \& Fax: +86 57188086706. 


\section{Abstract:}

From the aqueous extract of Semen Armeniacae Amarum, a major protein isolate

3 was purified and characterized as a novel member of the $11 \mathrm{~S}$ globulin family, which is

4 composed of three polypeptides linked by disulfide bond. Furthermore, the feasibility

5 of using the isolated protein for fabricating nanocarriers was investigated. The results

6 indicate that thermal treatment of the globulin induced the rearrangement of the

7 disulfide bond to form homodimers of acid polypeptides during the formation of

8 nanoparticles. The harvested nanoparticles produced by heat-induced assembly are

9 spherical in shape, with an average size of $92 \mathrm{~nm}$ and exhibited low cytotoxicity to L-

1002 and MDCK cell lines. These nanoparticles are capable to encapsulate paclitaxel,

11 estimated the maximum encapsulation efficiency of paclitaxel loaded to the

12 nanoparticles was $92.6 \%$ and the maximum release of paclitaxel was $57.4 \%$. This

13 research suggests that the screening of traditional herbal extracts could provide a novel

14 source of protein nanocarriers.

15

16 KEYWORDS: protein nanoparticles; thermal assembly; disulfide bond. 


\section{Introduction}

The plant kingdom contains many substances which may have therapeutic potential for the prevention or treatment of human diseases. However, these bioactive ingredients (e.g. vitamins and alkaloids) often exhibit low bioavailability and chemical or biological instability [1]. Recently, various technics of improve drug delivery were developed to address these weakness in bioavailability and stability [2]. One concept of controlled drug delivery involves the association of active molecules with a carrier system [3]. Nanoparticles (NPs) are the most promising drugs carrier that may allow efficient delivery of bioactive compounds and achieve an increase in bioavailability [4]. Among NPs, protein-based NPs have special interests because of their advantage in being biodegradable through metabolic processes [5]. Protein NPs have unique properties compared to other NPs since they are derived from natural sources, are easy to manipulate, and most importantly, are usually nontoxic [6]. The properties of protein NPs can be manipulated by adjusting $\mathrm{pH}$, temperature, protein concentration, etc., which are suitable for scale production. Natural food proteins, i.e., whey protein, casein and legumin, have been studied for their tendency to encapsulate either hydrophobic or hydrophilic molecules by heat-induced, calcium ion-induced or $\mathrm{pH}$-induced approaches [7-9]. Besides these food-derived proteins, herbal proteins remain as an untapped resource of raw materials for protein nanoparticles. It is well known that "decocting" which refers to boiling water extracts of herbs, often results in generation of micro- or nano-scale colloidal particles $[10,11]$. The investigations on these herbal colloidal particles has revealed that herbal proteins are the main contributors for the formation of nanoparticles among the macromolecules [12]. Up to now, herbal proteins in herbal decoctions were scarcely studied, since neither their bioactivities nor their structures were believed to be conserved after boiling.

Semen Armeniacae Amarum (SA), commonly known as bitter apricot kernel, is the dry ripe seed obtained from several plants of the Rosaceae family, including Prunus armeniaca L. var. ansu Maxim., P. sibirica L., P.mandshurica (Maxim.) Koehne and P. armeniaca L [13]. Bitter apricot kernel is a popular food ingredient and a widelyused ingredient for traditional Chinese medicine (TCM) formulas. Its annual production is about 193,000 metric tons in China [14], which are mainly used for oil extraction and in protein drinks after detoxification [15]. A by-product of the kernel oil processing, 
bitter apricot kernel meal, which contains approximately $34 \%$ crude protein [16], but has rarely been investigated for use as a functional food ingredient.

Most plant seeds contain 11S globulins as major storage proteins for nutrients [17]. Globulins are used in a wide range of practical applications not only because of their biological activity but also because of their inherent properties. These protein molecules would unfold and interact to form covalent NPs at sufficiently high temperatures [18]. As a nano-carrier needs to be stable in the circulatory system, the interchain disulfide linkage between subunits is the ideal stabilization strategy [19]. Hence, the conformational features protein NPs exhibit potential to be used as functional NPs to deliver bioactive components, especially for hydrophobic drugs.

Paclitaxel (PTX) is one of the most widely used antineoplastic drugs found from nature in the past decades [20], has demonstrated significant activity against a variety of tumors, such as metastatic breast cancer [21]. However, PTX is a hydrophobic drug with poor aqueous solubility. To increase its solubility for clinical applications, nanotechnology has been used to design the PTX-loading carrier, such as nanoencapsulation [22], nanoemulsions [23] and nanocrystals [24]. The use of chemical cross-linking agents to the stabilize nano-carrier is challenging due to its potential toxicity. For this reason, a natural material with appropriate properties needs to be developed.

In this study, the major proteins/subunits of Semen Armeniacae Amarum (SAP) were isolated and purified by chromatography; the characterization of proteins was measured by electrophoresis, mass spectrometry and $\mathrm{N}$-terminal amino acid sequencing. The SAP nanoparticles (SAP-NPs) were assembled by thermal treatment, and the effect of medium $\mathrm{pH}$ value, heating temperature, heating time and SAP concentration were systematically evaluated. The SAP-NPs features were characterized by morphology, size and surface charge. The mechanism of assembly was analyzed based on an investigation of structure dissociation in the presence of urea, dithiothreitol (DTT) and sodium dodecyl sulphate (SDS). The PTX loading and release tests were carried out, and cytotoxicity of SAP-NPs was evaluated by the MTT test in vitro using human normal liver cells (L-02) and Madin-Darby canine kidney (MDCK) cells. 


\section{Materials and methods}

\subsection{Materials}

Semen Armeniacae Amarum (SA) was purchased from Beijing Yanjing Chinese Medicinal Herbs Co. Ltd. (China). BCA kit was purchased from Nanjing Jiancheng Bioengineering Institute (China). High $\mathrm{Q}$ ion exchange gel was purchased from BioRed Laboratories (USA). The TSK-GEL G6000 PW column was purchased from TOSOH (Japan). $\beta$-Mercaptoethanol was purchased from Amresco Co. (USA). Paclitaxel (99.5\% purity), sodium dodecyl sulphate, glycine and Trizma base were purchased from Sigma Chemical Co. (USA). Ethanol, acetone, carbamide, hydrochloric acid, glacial acetic acid, sodium chloride, $N, N, N^{\prime}, N^{\prime}$-Tetramethyl ethylene diamine, tween 20, bromophenol blue, ammonium persulphate and EDTA were purchased from Sinopharm Chemical Reagent Co., Ltd (China).

\subsection{Purification of SAP}

After the Semen Armeniacae Amarum was ground and defatted with acetone (1:10 $\mathrm{w} / \mathrm{v}$ ) for $4 \mathrm{~h}$, the residual acetone in the slurry was then evaporated overnight at $4{ }^{\circ} \mathrm{C}$. The defatted powder was homogenized in $10 \mathrm{mM}$ phosphate buffer $(\mathrm{pH} 7.4,1: 50 \mathrm{w} / \mathrm{v})$ for $1 \mathrm{~h}$. After centrifugation at $6000 \mathrm{~g}$ for $10 \mathrm{~min}$, the crude protein solution was then purified by a two-step chromatographic method using High Q anion exchange chromatography and TSK-GEL G6000 PW gel filtration chromatography. $5 \mathrm{~mL}$ of defatted protein solution was loaded onto a High Q anion exchange column equilibrated with Tris-HCl buffer $(20 \mathrm{mM}, \mathrm{pH} 8.1)$ and then eluted with a linear gradient of $\mathrm{NaCl}$ $(0-0.3 \mathrm{M})$ contained in Tris- $\mathrm{HCl}(20 \mathrm{mM}, \mathrm{pH} 8.1)$ buffer in a total volume of $150 \mathrm{~mL}$ at $1.0 \mathrm{~mL} / \mathrm{min}$. Fraction SP1 was collected and then dialyzed against $50 \mathrm{mM}$ phosphate buffer ( $\mathrm{pH} 8.1$ containing $0.02 \% \mathrm{NaN}_{3}$ ). Then $50 \mu \mathrm{L}$ of dialyzed SP1 was subsequently purified by gel filtration chromatography with phosphate buffer in a total volume of 30 $\mathrm{mL}$ at $0.5 \mathrm{~mL} / \mathrm{min}$. The eluate was monitored at UV $280 \mathrm{~nm}$. Fraction SP2 was obtained and collected for further study. The protein concentration was determined using a BCA kit. Bovine serum albumin (BSA) was used as the protein standard.

Three polypeptides were collected by preparative SDS-PAGE using the AE-6760 preparation system (ATTO, Japan) connected to a micro collector (ATTO, Japan). After concentrating gel $(\mathrm{T}=5 \%)$ and separating gel $(\mathrm{T}=10 \%)$ were cast in the tapered tube assembly, the concentrated protein sample $(\sim 30 \mathrm{mg})$ was loaded onto the top of the gel 
112 avoiding bubbles. The power supply was set at a constant rate of $30 \mathrm{~mA}$, and the

113 Tris/glycine/SDS running buffer was eluted at $1 \mathrm{~mL} / \mathrm{min}$. The micro collector was 114 started running after eluting for $6 \mathrm{~h}$ and the fractions were collected for $1 \mathrm{~mL}$ per tube.

\section{$115 \quad 2.3$ Characterizations of SAP}

116 Total proteins and chromatography resulting fractions were analyzed by SDS117 PAGE. It was performed by using concentrating gel $(\mathrm{T}=4 \%)$ and separating gel $118(\mathrm{~T}=12.5 \%)$ in an electrophoretic system (ATTO, Japan). Reducing conditions were 119 obtained by adding DTT (20 mmol/L) in sample buffer. A $30 \mu \mathrm{L}$ sample was loaded 120 and the gels were run in Tris/glycine/SDS buffer. The gels were stained with Coomassie 121 Brilliant Blue R 250 and were examined using a scanning instrument (PeiQing, China). 122 The isoelectric focusing (IEF)-PAGE was performed using a 2-dimensional 123 electrophoresis system (ATTO, Japan). The gels were stained with Coomassie blue 124 R250. The molecular weights of polypeptides were determined by a Matrix-Assisted 125 Laser Desorption/Ionization Time of Flight (MALDI-TOF) mass spectrometer 126 (Applied Biosystem, USA). The amino acid sequence of three purified polypeptides 127 was sequenced by Edman degradation using a protein sequencer (Shimadzu, Japan).

\section{$128 \quad 2.4$ Preparation and characterizations of SAP-NPs}

After dialyzing with distilled water, the purified SAP was lyophilized and used to prepare the SAP-NPs. The NPs formation was examined by varying $\mathrm{pH}$ (2-10) with

$1311 \mathrm{mg} / \mathrm{mL} \mathrm{SAP}$ solution at $95{ }^{\circ} \mathrm{C}$ for $10 \mathrm{~min}$; varying protein concentration $(0.25,0.5,1$,

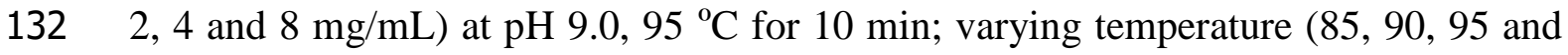
$133100{ }^{\circ} \mathrm{C}$ ) with $1 \mathrm{mg} / \mathrm{mL}$ SAP solution heating for $10 \mathrm{~min}$; varying heating time (10-60 $134 \mathrm{~min}$ ) with $1 \mathrm{mg} / \mathrm{mL}$ SAP solution at $\mathrm{pH} 9.0,95{ }^{\circ} \mathrm{C}$. All samples were cooled down 135 immediately in ice after the heating process to terminate the assembly formation.

136 The Z-average diameter (ZD), Zeta-potential, polydispersity index (PDI), derived 137 count rate (DCR), Zeta potential (Zeta P) and distribution of light scattering spectrum 138 intensity of SAP-NPs were measured using a Zetasizer Nano ZS (Malvern, UK).

139 The microstructure of NPs was observed by a JEM-1230TEM (JEOL, Japan). 20 $140 \mu \mathrm{L}$ sample was dispensed onto a carbon-coated copper grid and then stained with $2 \%$ $141(\mathrm{w} / \mathrm{v})$ uranyl acetate for $5 \mathrm{~min}$.

$142 \quad 2.5$ Protein thermal analysis 
Protein conformational changes before and after NPs formation were measured by

144 Far-UV CD spectra. CD was acquired in the range of 190-250 nm using a J-710 145 spectropolarimeter (JASCO, Japan) with Quartz cuvettes path length of $1 \mathrm{~cm}$. The 146 spectral resolution was $0.5 \mathrm{~nm}$, time per point $1 \mathrm{~s}$, bandwidth $1 \mathrm{~nm}$. The data were 147 calculated by Spectra Manager software. The thermal properties of SAP were examined 148 using a VP-DSC thermal analyzer (Malvern, UK). Approximately $1 \mathrm{mg}$ of protein were heated in aluminum pans from 15 to $100^{\circ} \mathrm{C}$ at a rate of $10^{\circ} \mathrm{C} / \mathrm{min}$.

150

151

152

153

154

155

156

157

158

159

160

161

162

163

164

165

166

167

168

169

170

171

\subsection{Nanoparticles dissociation testing}

$\beta$-Mercaptoethanol ( $\beta$-ME), urea and SDS were chosen to investigate the molecular interactions to form SAP-NPs such as $\beta$-ME for breaking disulfide bonds, urea for attenuating hydrogen bonds and SDS for attenuating hydrophobic interactions. The reagents were respectively added to SAP solutions at final concentrations as following, $2 \%(\mathrm{w} / \mathrm{w})$ for $\beta$-mercaptoethanol, $6 \mathrm{M}$ for urea and $10 \mathrm{mM}$ for SDS, the concentrations of these denaturing reagents was determined according to the previous studies $[25,26]$. The mixtures were heated and kept at $95^{\circ} \mathrm{C}$ for $10 \mathrm{~min}$, and then subjected to diameter distribution proportion analyses by dynamic light scattering. The reagents were also added to SAP-NPs to investigate their influences on the structures.

\subsection{PTX loading and release}

A predetermined amount of PTX were dissolved in methanol and added to SAP solution with the PTX/SAP weight ratios (w/w) of 2.5\%, 5\%, 10\%, 20\% and 50\%, respectively. The mixtures were heated in a water bath at $95{ }^{\circ} \mathrm{C}$ for $10 \mathrm{~min}$ and cooled to $25^{\circ} \mathrm{C}$ immediately. Non-entrapped PTX was removed by ultrafiltration (with MW cut-off of $100 \mathrm{kDa}, 5000 \mathrm{~g}, 30 \mathrm{~min}$ ). The SAP-NPs on the ultrafiltration membrane were washed and resuspended in an aqueous dispersion. The amount of PTX was analyzed by high performance liquid chromatography (Bio-Red Laboratories, USA) equipped with a Phenomonex C18 (5 $\mu \mathrm{m}, 150 \times 4.6 \mathrm{~mm})$ column (USA) according to the method of Ahmed Abu-Fayyad et al. [27]. Encapsulation efficiency (EE\%) and PTX loading content were calculated by the following equation: 
The in vitro release testing of paclitaxel from SAP-NPs was carried out by a 174 dialysis tube method described by Federica Novelli et al. [28]. A $0.5 \mathrm{~mL}$ sample of 175 PTX loaded SAP-NPs in PBS buffer (pH 7.4, $10 \mathrm{mM})$ was introduced into a dialysis 176 tube with MW cut-off of 8-14 kDa. The dialysis tube then was dialyzed against PBS 177 buffer containing $5 \%$ Tween $20(\mathrm{w} / \mathrm{v})$ in a beaker. The beaker was maintained at $37{ }^{\circ} \mathrm{C}$ and gently stirred $(100 \mathrm{rpm})$ for $48 \mathrm{~h}$. The release media were replaced with fresh release media of equal volume at regular intervals. Quantification of PTX in release medium was performed by HPLC as described above.

L-02 and MDCK cells were seeded into 96-well plates (Costar, Corning, NY) at a density of $5 \times 10^{4}$ cells/well in the MEM medium. Prior to incubation, SAP and SAPNPs was added in varied SAP concentrations of $0.25,0.5,1.0$ and $2.0 \mathrm{mg} / \mathrm{mL}$ with 4 duplicates for each concentration. Control group were treated with PBS buffer (20 mM, $\mathrm{pH}$ 9.0). The 96-well plates then were incubated at $37^{\circ} \mathrm{C}$ with $5 \% \mathrm{CO}_{2}$ for $24 \mathrm{~h}$. The cellular viability was then assessed by cell proliferation (MTT assay) (Loosdrecht et al., 1994), and presented as the percentage of viable cells (Means $\pm S D, n=4$ ) given by:

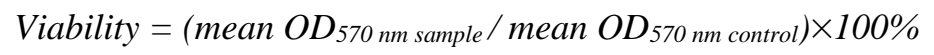

\subsection{Statistical analysis}

All experiments were performed at least three times. Data were analyzed by Origin imaging software (Origin pro 2017, Inc., USA). Results were expressed in tables as mean \pm standard deviation (SD). Error bars represent SD on figures. The significance levels were examined with Student's t-test and ranked as $P<0.05$.

\section{Results and discussion}

\subsection{Purification of SAP}

The SDS-PAGE result of aqueous extract is presented in Figure 1 (a), the majority of proteins was observed at an approximate molecular weight $(\mathrm{Mw})$ of $65 \mathrm{kDa}$, appeared within band A (named SAP) compared to several other weak bands. The protein electrophoresis pattern was obviously changed by boiling the aqueous extract, 
shown in lane 2. The appearance of new protein bands in four regions, marked by B-E, was coincident with the diminution of band A, suggesting that heating process changed the protein structures (i.e., quaternary structures). The proteins within region $\mathrm{D}$ and $\mathrm{E}$ have relatively smaller $\mathrm{Mw}$ compared to $\mathrm{SAP}$, which may represent the polypeptides composed of SAP. The proteins within region B have larger Mw, which implied the recombination or re-arrangement among the polypeptides of SAP. This resulted in forming huge protein complexes or aggregates and their sizes are too large to pass through the separating gel (as shown in region C). The purification and characterization SAP were carried out to understand the transformation among the subunits of SAP by heating and their heating-induced assembly.

The crude protein solution was subjected to anion exchange and gel filtration chromatography for further purification (Figure $1 \mathrm{~b}-\mathrm{c}$ ), fraction SP2 containing SAP was obtained. The results of SDS-PAGE (Figure $1 \mathrm{~d}$ ) showed that SAP contains two proteins (non-reducing conditions) with $\mathrm{Mw}$ of 65.9 and $64.2 \mathrm{kDa}$, respectively. Furthermore, these two proteins consisted of three polypeptides with Mws of 45.3, 43.6 and $20.6 \mathrm{kDa}$ under reducing conditions, suggesting that they are heterodimers. Each of them contains two polypeptides linked by an interchain disulfide bond, one of the polypeptides with $\mathrm{Mw}$ of $20.6 \mathrm{kDa}$ shared by these two proteins. It also revealed that the interchain disulfide bonds were broken by heating, shown in lane 2 of Figure 1 (a).

220 Subsequently, three polypeptides were purified by preparative SDS-PAGE under 221 reducing conditions, and were subjected to IEF, MALDI-TOF and N-terminal amino acid sequencing (Shown in Table 1). Each N-terminal amino acid sequence was compared to sequences in NCBI databases using the BLAST suite of programs. They were detected and possessed a high degree of sequence similarity with a sequence deduced from a cDNA clone, which encoded the almond 11S globulin precursor Pru1. The AP-1 and AP-2 owned the same $10 \mathrm{~N}$-terminal amino acid sequence of ARQSQLSPQN, which was totally identical to a region within the Pru1 N-terminal sequence. The BP-1 displayed the highest homology with a motif starting from residue A248 of Pru1 containing a NGxEET motif of 11S globulins [29]. 11S globulins typically are hexamer consisting of acidic and basic polypeptide chains, which are covalently linked by disulfide bond. The masses of the acidic chains are typically $\sim 40 \mathrm{kDa}$, while the basic chains usually have masses of $\sim 20 \mathrm{kDa}[30,31]$. In our case, the hexamer of $11 \mathrm{~S}$ globulin is compose of two types of subunits. The SAP fraction is 
234 the mixture of these two subunits, whose acidic polypeptide chains are AP-1 and AP-2,

235 while both of their basic polypeptide chains are BP-1.

\subsection{The influences on protein structures by heating}

Heat treatment led to a thermal denaturation of protein and induced the exposure of initially embedded hydrophobic amino acids and sulfhydryl groups that are responsible for NP formation. To study the relationship between unfolding of thermally induced protein and particle formation, circular dichroism (CD) spectra were obtained at the far UV range to trace the secondary structure of SAP as affected by heating (shown in Figure 2 a). The unheated sample exhibited a strong positive peak at 190-200 $\mathrm{nm}$ and a broad negative peak in the region of $205-215 \mathrm{~nm}$. The secondary structure of the unheated SAP composed of $6.2 \% \alpha$-helix, $73 \% \beta$-sheet and $20.8 \%$ random structures. When the SAP was heated for $10 \mathrm{~min}$, the peak at $195 \mathrm{~nm}$ was vanished and the negative peak was shifted towards lower wavelength with slight increase. This may be caused by the release of monomers from the protein during heat treatment [32]. There was about $4.1 \%$ of $\alpha$-helix converted to random structures, while $\beta$-sheet remained unchanged, which was probably because the SAP retained much of the intramolecular $\beta$-sheet structure when heated at $95^{\circ} \mathrm{C}, \mathrm{pH} 9.0$ for $10 \mathrm{~min}$. The thermal behavior of SAP was studied by differential scanning calorimetry (DSC) that is illustrated in Figure 2 (b). A single peak of thermal transition midpoint (Tm) was observed, indicating a denaturation of SAP at $76.31{ }^{\circ} \mathrm{C}$. SAP was denatured and participated in the formation of large protein complex at a temperature above the Tm value. Therefore, these conformational features of thermal treatment could be used in the development of custom-made carrier.

On the other hand, the disulfide bonds among polypeptides were also influenced by thermal treatment. As seen in Figure 2 (c), the result of SDS-PAGE showed that the interchain disulfide bonds of SAP were broken down after heating at $95{ }^{\circ} \mathrm{C}$ for $10 \mathrm{~min}$, indicated by the occurrence of the polypeptides with $\mathrm{Mw} 45$ and $43 \mathrm{kDa}$ under nonreducing conditions. Meanwhile, either of these two polypeptides was able to form homodimer via an interchain disulfide bond, revealed by the occurrence of two new protein fractions which exhibited two bands with $\mathrm{Mw} \sim 90$ and $\sim 86 \mathrm{kDa}$ in non-reducing 
SDS-PAGE and 45 and $43 \mathrm{kDa}$ bands in reducing SDS-PAGE. The results suggested that the subunits with Mw of 45 and $43 \mathrm{kDa}$ were released from SAPs and able to form homodimers upon heating, respectively. Notably, after heat treatment, while the band intensity of $66 \mathrm{kDa}$ reduced and the band of $45 \mathrm{kDa}$ occurred, which indicated the breakdown of disulfide bridges, the band of BP-1 was not observed in SDS-PAGE, which suggested that BP-1 were precipitated by heat treatment. The thermal instability of the basic polypeptides was also reported in Amandin [26].

\subsection{Preparation of SAP-NPs by heating-induced assembly}

Due to their sizes, nanoparticles have large surfaces per unit volume to improve the bioavailability, delivery properties and stability for drug and thus their biological activity [33]. The scale of nanoparticles can be modulated by controlling the various factors, such as protein concentration, $\mathrm{pH}$, heating time and temperature. In addition, $\mathrm{pH}$ conditions also significantly influence the protein interactions. At pHs far away from its pI, protein molecules repel to each other due to electrostatic repulsion. solution was heated in the $\mathrm{pH}$ range $2-6$, an obvious precipitate was noticed and the supernatant showed very low light scattering spectrum intensity (data not shown). As can be seen in Figure 3 (a), the Z-average diameter (ZD) at $\mathrm{pH} 7.0$ was $42.3 \mathrm{~nm}$, the DCR was about 4000 , indicating that no obvious colloids were produced by heating at $\mathrm{pH}$ 7.0. When increasing the $\mathrm{pH}$ value to around $\mathrm{pH}$ 8.0-9.0, the formation of protein NPs with size ranged from $90-92 \mathrm{~nm}$ was observed. The PDI value was less than 0.2 at $\mathrm{pH}$ 9.0, whereas the PDI was near to 0.34 at $\mathrm{pH}$ 8.0, implying that the formation of NPs at $\mathrm{pH} 9.0$ were more homogeneously dispersed than those of $\mathrm{pH}$ 8.0. When the $\mathrm{pH}$ was above 10.0, the ZD of the particle became larger with an obvious decrease in DCR and less NPs were formed. The results suggest that the proteins were unfolded and its content of ordered structures, e.g. $\alpha$-helix, were decreased, while heating above $\mathrm{pH}$ 7.0, conformational changes could influence on their aggregation [34]. It is worth 291 mentioning that the protein molecules have a great charge density, which increases intermolecular repulsion at extreme $\mathrm{pH}$ values. Therefore, the protein NPs can be 293 formed by assembly with a balance between electrostatic repulsion and intermolecular 
hydrophobic attraction [35].

The size and PDI of particles at different protein concentration were determined and shown in Figure 3 (b). The particle sizes increased with the increase of the protein concentration, and aggregates or even precipitation were observed when the protein concentration exceeded $4.0 \mathrm{mg} / \mathrm{mL}$ accompanied with the significant decrease of DCR values. The PDI pattern was narrower than those at other concentrations when the ZD of NPs was about $92 \mathrm{~nm}$ at protein concentration of $1.0 \mathrm{mg} / \mathrm{mL}$, and the DCR was also the highest among the protein concentrations. Hence, the SAP protein concentration for heat-induced assembly of NPs was optimized as $1.0 \mathrm{mg} / \mathrm{mL}$.

The influence of temperature and heating time on assembly of SAP-NPs was investigated. According to Tm of $76.3{ }^{\circ} \mathrm{C}$ determined by DSC, the SAP solutions (pH 9.0, $\mathrm{C}=1.0 \mathrm{mg} / \mathrm{mL}$ ) were heated at the temperature of $85^{\circ} \mathrm{C}, 90{ }^{\circ} \mathrm{C}, 95^{\circ} \mathrm{C}$ and $100{ }^{\circ} \mathrm{C}$. As shown in Figure 3 (c), the particle size increased with the increase of heating temperature in the range from 85 to $100{ }^{\circ} \mathrm{C}$. The DCR values increased dramatically when the temperature rose from 90 to $95{ }^{\circ} \mathrm{C}$. A further increase of temperature to 100 ${ }^{\circ} \mathrm{C}$ did not affect the DCR values. The PDI at $95^{\circ} \mathrm{C}$ reached to the minimum among the tested temperatures. As demonstrated in Figure 3 (d), heating time showed little influence on the formation of SAP-NPs, while the ZDs and PDIs were slightly increased

312 with the extension of heating time, the DCRs were slightly decreased. Considering the preference of smaller scale, higher intensity of light scattered and narrower dispersion,

314 the optimal heating conditions for fabricating SAP-NPs were then selected at $95^{\circ} \mathrm{C}$ for $31510 \mathrm{~min}$. In summary, $1 \mathrm{mg} / \mathrm{mL}$ of SAP heated at $95^{\circ} \mathrm{C}$ for $10 \mathrm{~min}$ at $\mathrm{pH}$ of 9.0 formed 316 the SAP-NPs with well monodispersed particle distributions and optimum diameter of 317 approximately $92 \mathrm{~nm}$ under the optimum conditions.

\subsection{Morphology and Stability of Nanoparticles}

Figure 4 (a) showed the morphology of the SAP-NPs by TEM. SAP-NPs are spherical in shape with uniform size around $80 \mathrm{~nm}$. It was observed in Figure 4 (b) that

321 the size distribution for DLS analysis exhibited a unimodal and narrow pattern, which 322 implied that heating could be an effective monodisperse approach to produce uniform 
SAP-NPs. The result showed that SAP-NPs have a Zeta-potential of $-26 \mathrm{mV}$ and a Zaverage diameter (ZD) of $92 \mathrm{~mm}$. It is notable that the NPs size observed by TEM was apparently smaller compared to that by DLS (correspond to hydrodynamic diameter). It is probably due to extension of attached hydrophilic groups in aqueous medium.

327 Similar observations were reported by Vrushti Kansara [36].

\subsection{Nanoparticle formation and dissociation testing}

Internal bonds which are responsible for the formation of SAP-NPs have been investigated on dispersion in varied denaturing reagents [37]. The denaturing reagents were mixed with SAP solution and heated to form NPs at $95^{\circ} \mathrm{C}$ for $10 \mathrm{~min}$, respectively. The effects of various reagents on the dissociation of SAP-NPs was presented in Table 2. After incubation with $\beta$-ME, SAP was precipitated instead of forming soluble NPs. By mixing with either SDS or urea, SAP was assembled into nanostructures with size distribution of 1-5 nm and 10-30 nm, which were smaller than NPs with Z-average diameter of $92 \mathrm{~nm}$. The results suggested that disulfide bonds, hydrogen bonding and hydrophobic interactions are all important for heat-induced assembly of SAP-NPs. Among these three intermolecular forces, disulfide bonds are essential for formation of SAP nanostructures. Besides, the breakage of disulfide bonds cleaved by $\beta$-ME also prevented the formation of homodimers of the basic chains with molecular weight of 86 and $90 \mathrm{kDa}$, which implied that SAP-NPs are assembled by the homodimers via hydrogen bonding and hydrophobic.

The diameter distribution proportion analyses of SAP-NPs were carried out after incubation with the denaturing reagents to investigate the internal bonds within SAPNPs. As shown in Table 2, nearly $60 \%$ of SAP-NPs were broken down into smaller pieces after treatment with SDS, implying that smaller nanostructures with size of 1-5 $\mathrm{nm}$ and 10-30 $\mathrm{nm}$ were assembled via hydrophobic interaction. In contrast, neither $\beta$ ME nor urea influenced the size distribution of SAP-NPs. The hydrogen and disulfide bonds are less important to maintain the intact structural integrity of SAP-NPs compared to hydrophobic bonds. It might be due to the conformation of SAP-NPs, which embed their disulfide bonds and hydrogen bonds into their internal structures so that the SAP-NPs were able to resist to the presence of $\beta$-ME and urea.

Based on the results above, an idealized schematic representation of thermally induced self-assembly of SAP is given as Figure 5. During thermal treatment, the 
355 disulfide bonds of both subunits were broken, resulting in releasing of a basic 356 polypeptide with $\mathrm{Mw}$ of $20 \mathrm{kDa}$ and two acidic polypeptides with Mw of 45 and 43 $357 \mathrm{kDa}$, respectively. Both the released acidic polypeptides tend to subsequently form new 358 homodimers with $\mathrm{Mw}$ of 86 and $90 \mathrm{kDa}$ (also as shown in Figure 2 c) via disulfide 359 bonds. Upon thermal treatment, the homodimers assemble into nanoparticles. In 360 addition, the CD spectra indicated that the secondary structure of SAP was changed by 361 heat (as shown in Figure 2 a), the unfolding of secondary structure (the decrease of $\alpha$ 362 helix) led to the exposure of hydrophobic groups, which can enhance the hydrophobic 363 interactions during the formation of the SAP-NPs.

\subsection{Cytotoxicity evaluation}

The toxicities of SAP and SAP-NPs towards L-02 cell and MDCK cell was evaluated by MTT assay, shown in Figure 6 (a). The results suggested that the cellular viability of SAP-NPs exhibited little cytotoxicity on L-02 cell and MDCK cell at the concentration as high as $1 \mathrm{mg} / \mathrm{mL}$. The non-toxic concentrations of purified SAP for L-

36902 cell and MDCK cell both were $1 \mathrm{mg} / \mathrm{mL}$ for comparison. Therefore, the selfassembled nanostructures of the SAP proteins did not significantly change their cyto-

371 toxicities. The results of cytotoxicity also indicated that the SAP-NPs were safe nano-

372 vehicle for active ingredients delivery.

\subsection{Drug loading and in vitro releasing}

Paclitaxel (PTX) was employed to evaluate the potential of SAP-NPs as carrier for water-insoluble drugs in this study. PTX-loaded SAP-NPs were prepared with varied PTX/SAP weight ratio (w/w) by heat-induced assembly at $95{ }^{\circ} \mathrm{C}$ for $10 \mathrm{~min}$, the loading content of PTX was subsequently determined by a HPLC-based method and the encapsulation efficiency was calculated. Table 3 summarized the encapsulation characteristics of PTX-SAP-NPs. It was seen that the PTX to SAP mixtures in different PTX/SAP ratios were able to assemble into micro/nanoparticles by the heat-induced

381 method, and the particles sizes increased from $213 \mathrm{~nm}$ to $945 \mathrm{~nm}$ with the increase of 382 PTX/SAP ratio. In contrast, the encapsulation efficiency was reduced with the increase of PTX/SAP ratio, and the maximum encapsulation efficiency of $92.6 \pm 2.0 \%$ was obtained while the PTX/SAP ratio was 0.03. The maximum loading content of PTX was 9.38 wt.\%, whereas the PTX percent and EE\% were $10 \%$ and $84.5 \%$, respectively. 
When PTX/SAP ratio rose beyond 0.1, the EE\% decreased significantly and the loading content of PTX also decreased. The surface charge appeared to be important in determining whether the NPs adhered to other molecules with opposite charge. The absolute values of zeta-potential slightly increased with the increase of the PTX content, which suggested that more PTX was entrapped into SAP-NPs to form the stable PTXSAP-NPs complexes.

The PTX release test for PTX-SAP-NPs, which was assembled with PTX/SAP ratio of $1 / 20$, was carried out at $37^{\circ} \mathrm{C}$ for 50 hours in vitro in $10 \mathrm{mM}$ phosphate buffer ( $\mathrm{pH} 7.4$ ) containing 5\% w/v Tween 20 to prevent the sink condition [38]. As shown in Figure 6 (b), the release pattern composed of a fast growth phase in the first 20 hours, followed by a stabilizing phase in the last 30 hours. There was about $12.6 \%$ loaded PTX released from PTX/SAP-NPs during the first $1 \mathrm{~h}$. The release was then gradually increased until $20 \mathrm{~h}$ and remained constant even after $30 \mathrm{~h}$. The largest release percentage was observed for SAP-NPs loaded with free PTX was $57.4 \%$ for the drug. Chitosan is often used to fabricate nanocarrier with a high paracellular permeability, it was reported the PTX encapsulation efficiency was as high as $88.3 \%$ to the optimized chitosan nanoparticle, and the released amount of PTX was over 50\% within $24 \mathrm{~h} \mathrm{[39].}$ Compared with chitosan nanocarrier, SAP-NPs exhibited a higher encapsulation efficiency and more promising sustained release potential. The next work will focus on the delivery and release in vivo.

\section{Conclusion}

In summary, the major protein fraction SAP from the aqueous extract of Semen Armeniacae Amarum was purified and identified as a new member of $11 \mathrm{~S}$ globulin family, which poses a heterohexamer composed of two types of subunits. Like most 11s globulins, both subunits are heterodimers, each consisting of a basic polypeptide chain and an acid polypeptide chain, which are covalently linked by a single disulfide bond. The SAP was assembled into NPs by heating at $95{ }^{\circ} \mathrm{C}$ for $10 \mathrm{~min}$ at $\mathrm{pH} 9.0$, to give SAP-NPs with a Z-average diameter in the range of 90-92 $\mathrm{nm}$ Thermal treatment disrupted the disulfide bonds of heterodimers and formed new disulfide bonds between same subunits to produce homodimers. The results of formation testing suggested that disulfide bonds are essential for the formation of SAP-NPs. SAP-NPs are capable of 
encapsulating bioactive components with low aqueous solubility, such as paclitaxel. It was estimated that the maximum encapsulation efficiency of PTX loaded to SAP-NPs was $92.6 \%$ and the maximum release of PTX was $57.4 \%$.

It is speculated that this study may provide a new insight into "decocting", which is the earliest and most popular method of preparation practice in traditional Chinese medicine. It is conceivable that major proteins formed NPs during the boiling process could encapsulated insoluble compounds and prevented their precipitation. From this perspective, "decocting" could serendipitously be a method for producing natural protein NPs and the screening of herbal extracts could provide new protein nanocarriers.

\section{Acknowledgements}

This work was supported by the National Key R\&D Program of China (2016YFD0400202).

\section{References}

[1] I.J. Joye, G. Davidov-Pardo, D.J. McClements, Nanotechnology for increased micronutrient bioavailability, Trends in Food Science \& Technology 40(2) (2014) 168-182. [2] P. Puligundla, C. Mok, S. Ko, J. Liang, N. Recharla, Nanotechnological approaches to enhance the bioavailability and therapeutic efficacy of green tea polyphenols, Journal of Functional Foods 34 (2017) 139-151.

[3] J.B. Ferrado, A.A. Perez, F.F. Visentini, G.A. Islan, G.R. Castro, L.G. Santiago, Formation and characterization of self-assembled bovine serum albumin nanoparticles as chrysin delivery systems, Colloids and surfaces. B, Biointerfaces 173 (2019) 43-51.

[4] C.P. Reis, A.J. Ribeiro, S. Houng, F. Veiga, R.J. Neufeld, Nanoparticulate delivery system for insulin: design, characterization and in vitro/in vivo bioactivity, European journal of pharmaceutical sciences : official journal of the European Federation for Pharmaceutical Sciences 30(5) (2007) 392-7.

[5] Mohamad Tarhini, Hélène Greige-Gerges, A. Elaissari, Protein-based nanoparticles: From preparation to encapsulation of active molecules, International journal of pharmaceutics 522(1-2) (2017) 172-197.

[6] L. Sagalowicz, M. Michel, I. Blank, O. Schafer, M.E. Leser, Self-assembly in food - A concept for structure formation inspired by Nature, Current Opinion in Colloid \& Interface Science 28 (2017) 87-95.

[7] F. Liu, S.-Y. Ou, C.-H. Tang, Ca 2+-induced soy protein nanoparticles as pickering stabilizers: Fabrication and characterization, Food Hydrocolloids 65 (2017) 175-186. [8] T.H. Cornelis G. de Kruif, Volker S. Urban, Andrei V. Petukhov, Casein micelles and their internal structure, Advances in colloid and interface science 171-172 (2012) 36-52.

[9] C. Schmitt, C. Bovay, A.M. Vuilliomenet, M. Rouvet, L. Bovetto, R. Barbar, C. Sanchez, Multiscale characterization of individualized beta-lactoglobulin microgels formed upon heat treatment under narrow $\mathrm{pH}$ range conditions, Langmuir : the ACS journal of surfaces and colloids 25(14) (2009) 7899-909. 
[10] Y. Zhuang, J. Yan, W. Zhu, L. Chen, D. Liang, X. Xu, Can the aggregation be a new approach for understanding the mechanism of Traditional Chinese Medicine?, Journal of ethnopharmacology 117(2) (2008) 378-84. [11] J. Zhou, G. Gao, Q. Chu, H. Wang, P. Rao, L. Ke, Chromatographic isolation of nanoparticles from Ma-Xing-Shi-Gan-Tang decoction and their characterization, Journal of ethnopharmacology 151(3) (2014) 1116-1123. [12] Q. Weng, X. Cai, F. Zhang, S. Wang, Fabrication of self-assembled Radix Pseudostellariae protein nanoparticles and the entrapment of curcumin, Food chemistry 274 (2019) 796-802. [13] Qiao C, Zhu Y, Su Z, L. C, Studies on the source plants of Semen ArmeniacaeAmarum and their distribution, China Journal of Chinese Materia Medica 18(1) (1993) 12-14.

[14] L. Wang, H. Yu, Biodiesel from Siberian apricot (Prunus sibirica L.) seed kernel oil, Bioresource technology 112 (2012) 355-8.

[15] P.C. Sharma, B.M. Tilakratne, A. Gupta, Utilization of wild apricot kernel press cake for extraction of protein isolate, Journal of food science and technology 47(6) (2010) 682-5. [16] X. Wen, F. Jin, J.M. Regenstein, F. Wang, Transglutaminase induced gels using bitter apricot kernel protein: Chemical, textural and release properties, Food Bioscience 26 (2018) 15-22.

[17] E. Bojorquez-Velazquez, G.J. Lino-Lopez, J.A. Huerta-Ocampo, A. Barrera-Pacheco, A.P. Barba de la Rosa, A. Moreno, N.A. Mancilla-Margalli, J.A. Osuna-Castro, Purification and biochemical characterization of $11 \mathrm{~S}$ globulin from chan (Hyptis suaveolens L. Poit) seeds, Food chemistry 192 (2016) 203-11.

[18] J.H. Martínez, F. Velázquez, H.P. Burrieza, K.D. Martínez, A. Paula Domínguez Rubio, C. dos Santos Ferreira, M. del Pilar Buera, O.E. Pérez, Betanin loaded nanocarriers based on quinoa seed $11 \mathrm{~S}$ globulin. Impact on the protein structure and antioxidant activity, Food Hydrocolloids 87 (2019) 880-890.

[19] W. Wang, Y. Huang, S. Zhao, T. Shao, Y. Cheng, Human serum albumin (HSA) nanoparticles stabilized with intermolecular disulfide bonds, Chemical communications 49(22) (2013) 2234-6.

[20] T. Khuroo, D. Verma, A. Khuroo, A. Ali, Z. Iqbal, Simultaneous delivery of paclitaxel and erlotinib from dual drug loaded PLGA nanoparticles: Formulation development, thorough optimization and in vitro release, Journal of Molecular Liquids 257 (2018) 52-68.

[21] J.H. Kim, Y.S. Kim, S. Kim, J.H. Park, K. Kim, K. Choi, H. Chung, S.Y. Jeong, R.W. Park, I.S. Kim, I.C. Kwon, Hydrophobically modified glycol chitosan nanoparticles as carriers for paclitaxel, Journal of controlled release : official journal of the Controlled Release Society 111(1-2) (2006) 228-34.

[22] P.N. Ezhilarasi, P. Karthik, N. Chhanwal, C. Anandharamakrishnan, Nanoencapsulation Techniques for Food Bioactive Components: A Review, Food and Bioprocess Technology 6(3) (2012) 628-647.

[23] J.P. Hélder D. Silva, Ana C. Pinheiroa, Francesco Donsì, Ana Teresa Serra,, G.F. Catarina M.M. Duarte, Miguel A. Cerqueira, António A. Vicente, Evaluating the behaviour of curcumin nanoemulsions and multilayer nanoemulsions during dynamic in vitro digestion.pdf, Journal of Functional Foods 48 (2018) 605-613.

[24] J. Park, B. Sun, Y. Yeo, Albumin-coated nanocrystals for carrier-free delivery of paclitaxel, Journal of controlled release : official journal of the Controlled Release Society 263 (2017) 90-101.

[25] P.F. HARSHAL H. KSHIRSAGAR, GIRDHARI M. SHARMA, KENNETH H. ROUX, SHRIDHAR K. SATHE, Biochemical and Spectroscopic Characterization of Almond and CashewNut Seed $11 \mathrm{~S}$ Legumins, Amandin and Anacardein, Journal of agricultural and food chemistry 59 (2002) 386-393. 
[26] S.M. Albillos, N. Menhart, T.J. Fu, Structural stability of Amandin, a major allergen from almond (Prunus dulcis), and its acidic and basic polypeptides, Journal of agricultural and food chemistry 57(11) (2009) 4698-705.

[27] A. Abu-Fayyad, M.M. Kamal, J.L. Carroll, A.M. Dragoi, R. Cody, J. Cardelli, S. Nazzal, Development and in-vitro characterization of nanoemulsions loaded with paclitaxel/gammatocotrienol lipid conjugates, International journal of pharmaceutics 536(1) (2018) 146-157. [28] F. Novelli, S. De Santis, P. Punzi, C. Giordano, A. Scipioni, G. Masci, Self-assembly and drug release study of linear I,d-oligopeptide-poly(ethylene glycol) conjugates, New biotechnology 37(Pt A) (2017) 99-107.

[29] M.R. Tandang-Silvas, T. Fukuda, C. Fukuda, K. Prak, C. Cabanos, A. Kimura, T. Itoh, B. Mikami, S. Utsumi, N. Maruyama, Conservation and divergence on plant seed $11 \mathrm{~S}$ globulins based on crystal structures, Biochimica et biophysica acta 1804(7) (2010) 1432-42.

[30] V. Gaur, D.K. Sethi, D.M. Salunke, Purification, identification and preliminary crystallographic studies of Pru du amandin, an allergenic protein from Prunus dulcis, Acta crystallographica. Section F, Structural biology and crystallization communications 64(Pt 1$)$ (2008) 32-5.

[31] Silvia M. Albillos, Tengchuan JIN, Andrew Howard, Yuzhu ZHANG, Mahendra H. Kothary, T. FU, Purification, Crystallization and Preliminary X-ray Characterization of Prunin-1, a Major Component of the Almond (Prunus dulcis) Allergen Amandin, Journal of agricultural and food chemistry 56 (2008) 5352-5358.

[32] SILVIA M. ALBILLOS, Nicholas Menhart, T. FU, Structural stability of Amandin, a major allergen from almond (Prunus dulcis), and its acidic and basic polypeptides, Journal of agricultural and food chemistry 57(11) (2009) 698-705.

[33] R. Parveen, T.N. Shamsi, S. Fatima, Nanoparticles-protein interaction: Role in protein aggregation and clinical implications, International journal of biological macromolecules 94(Pt A) (2017) 386-395.

[34] C. Tallian, A. Herrero-Rollett, K. Stadler, R. Vielnascher, K. Wieland, A.M. Weihs, A. Pellis, A.H. Teuschl, B. Lendl, H. Amenitsch, G.M. Guebitz, Structural insights into pH-responsive drug release of self-assembling human serum albumin-silk fibroin nanocapsules, European journal of pharmaceutics and biopharmaceutics : official journal of Arbeitsgemeinschaft fur Pharmazeutische Verfahrenstechnik e.V 133 (2018) 176-187.

[35] O.E. Sponton, A.A. Perez, J.V. Ramel, L.G. Santiago, Protein nanovehicles produced from egg white. Part 1: Effect of $\mathrm{pH}$ and heat treatment time on particle size and binding capacity, Food Hydrocolloids 73 (2017) 67-73.

[36] V. Kansara, R. Patil, R. Tripathi, P.K. Jha, P. Bahadur, S. Tiwari, Functionalized graphene nanosheets with improved dispersion stability and superior paclitaxel loading capacity, Colloids and surfaces. B, Biointerfaces 173 (2019) 421-428.

[37] C. Schmitt, C. Moitzi, C. Bovay, M. Rouvet, L. Bovetto, L. Donato, M.E. Leser, P. Schurtenberger, A. Stradner, Internal structure and colloidal behaviour of covalent whey protein microgels obtained by heat treatment, Soft Matter 6(19) (2010) 4876-4884. [38] L. Nothnagel, M.G. Wacker, How to measure release from nanosized carriers?, European journal of pharmaceutical sciences : official journal of the European Federation for Pharmaceutical Sciences 120 (2018) 199-211.

[39] Y. Han, N. Liang, P. Yan, Y. Kawashima, F. Cui, S. Sun, A Chitosan-Based Micellar System as Nanocarrier For the Delivery of Paclitaxel, Polymers (Basel) 12(2) (2020). 
553

554 Figure 1. Purification and characterization of SAP. (a) SDS-PAGE of extraction.

555 Lane: 1, molecular weight marker (non-reducing); 2, heated protein solution; 3,

556 natural protein extraction. (b) Anion exchange chromatography on High Q. The

557 unloaded fraction was washed with $30 \mathrm{~mL}$ and loaded protein was eluted with $120 \mathrm{~mL}$

558 linear $\mathrm{NaCl}$ gradient $(0-0.3 \mathrm{M})$. (c) Fraction peak SP1 was collected and loaded onto a

559 TSK-GEL G6000 PW gel filtration column, eluted by phosphate buffer (pH 8.1, 20

$560 \mathrm{mM}$ ). The protein content of the eluate was monitored at $280 \mathrm{~nm}$. (d) SDS-PAGE of

561 SAP with non-reducing and reducing. An enlarged view of SAP was diluted 20 times

562 by PBS buffer.

563

564 Figure 2. Thermal analysis of SAP. (a) Circular dichroism spectra of unheated and 565 heated SAP. (b) DSC thermograms of SAP. $C_{P}$ : heat capacity. (c) SDS-PAGE of 566 unheated and heated SAP with non-reducing and reducing. Lane: 1, molecular weight 567 marker (non-reducing); 2, unheated SAP solution; 3, heated SAP for 10 min at $95{ }^{\circ} \mathrm{C}$. 568

569 Figure 3. Influence of experimental conditions on fabrication of SAP-NPs. (a) pH. (b) 570 Protein concentration. (c) Temperature. (d) Heating time.

571

572 Figure 4. (a) TEM micrographs of SAP-NPs dispersions, the scale bar represents 100 $573 \mathrm{~nm}$. (b) Size distribution of SAP-NPs. The NPs prepared with $1 \mathrm{mg} / \mathrm{mL}$ SAP solution 574 (pH 9.0) heated at $95^{\circ} \mathrm{C}$ for $10 \mathrm{~min}$.

575

576 577

578 Figure 6. (a) Percentage of cell viability evaluated by MTT assay on L-02 and 579 MDCK. Control group were treated with PBS buffer. ${ }^{*} P<0.05$ compared with the 580 control group. (b) In vitro release profile of PTX from the loaded SAP-NPs. 
582 Table 1. N-terminal sequence, IEF and Molecular weight of SAP polypeptides.

\begin{tabular}{cccc}
\hline Polypeptides & N-terminal amino acid sequence & IEF & $\begin{array}{c}\text { Molecular weight } \\
(\mathrm{kDa})\end{array}$ \\
\hline AP-1 & ARQSQLSPQNQ & 5.44 & 45.31 \\
AP-2 & $\underline{\text { ARQSQLSPQNAYQLVQQQAR }}$ & 5.32 & 43.57 \\
BP-1 & $\underline{\text { GVEETFCSARLSQNIGDPS }}$ & 6.54 & 20.62 \\
\hline
\end{tabular}


587 Table 2. Effects of various reagents on the dissociation of SAP-NPs.

\begin{tabular}{ccccc}
\hline & Denaturing & \multicolumn{3}{c}{ Distribution proportion (\%) } \\
\cline { 3 - 5 } & reagents & $1-5 \mathrm{~nm}$ & $10-30 \mathrm{~nm}$ & $90-100 \mathrm{~nm}$ \\
\hline Heating with SAP & $2 \% \beta-M E$ & & $\mathrm{P}^{\mathrm{a}}$ & \\
solutions & $6 \mathrm{M}$ urea & 45.5 & 54.5 & $--\mathrm{b}$ \\
& $10 \mathrm{mM} \mathrm{SDS}$ & 33.2 & 66.8 & -- \\
Incubation with & $2 \% \beta-\mathrm{ME}$ & -- & -- & 100 \\
SAP-NPs & $6 \mathrm{M}$ urea & -- & -- & 100 \\
& $10 \mathrm{mM}$ SDS & 35.4 & 24.5 & 40.1 \\
\hline
\end{tabular}

$588 \quad{ }^{\mathrm{a}}$ Precipitation; ${ }^{\mathrm{b}}$ Not detected.

589 
590 Table 3. The encapsulation characteristics of PTX-SAP-NPs.

\begin{tabular}{|c|c|c|c|c|}
\hline Sample & $\begin{array}{l}\text { Encapsulation } \\
\text { Efficiency }(\%)\end{array}$ & $\begin{array}{l}\text { PTX loading } \\
\text { content }(\%)\end{array}$ & $\begin{array}{c}\text { Z- Average } \\
\text { diameter }(\mathrm{nm})\end{array}$ & $\begin{array}{c}\text { Zeta-potential } \\
(\mathrm{mV})\end{array}$ \\
\hline SAP-NPs & - & - & $91.54 \pm 2.01$ & $-26.1 \pm 0.3$ \\
\hline $\begin{array}{c}\text { PTX (2.5\%) SAP- } \\
\text { NPs }\end{array}$ & $92.6 \pm 2.0$ & $2.26 \pm 0.09$ & $213.07 \pm 2.60$ & $-28.2 \pm 0.3$ \\
\hline $\begin{array}{c}\text { PTX (5\%) SAP- } \\
\text { NPs }\end{array}$ & $90.3 \pm 3.1$ & $4.30 \pm 0.34$ & $305.45 \pm 4.05$ & $-29.3 \pm 0.6$ \\
\hline $\begin{array}{c}\text { PTX (10\%) SAP- } \\
\text { NPs }\end{array}$ & $84.5 \pm 2.4$ & $9.38 \pm 0.68$ & $416.92 \pm 6.72$ & $-30.6 \pm 0.4$ \\
\hline $\begin{array}{c}\text { PTX (20\%) SAP- } \\
\text { NPs }\end{array}$ & $34.2 \pm 3.5$ & $8.08 \pm 1.02$ & $421.77 \pm 5.98$ & $-31.2 \pm 0.6$ \\
\hline $\begin{array}{c}\text { PTX (50\%) SAP- } \\
\text { NPs }\end{array}$ & $16.7 \pm 1.1$ & $7.05 \pm 1.73$ & $945.23 \pm 8.81$ & $-31.0 \pm 0.9$ \\
\hline
\end{tabular}

591

592 
(a)

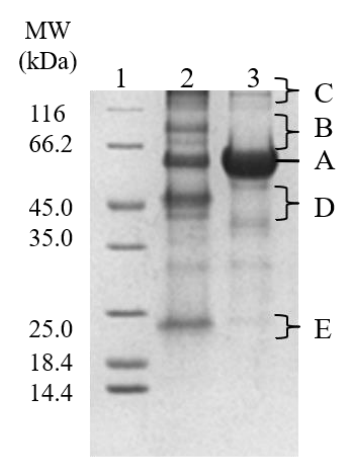

(c)

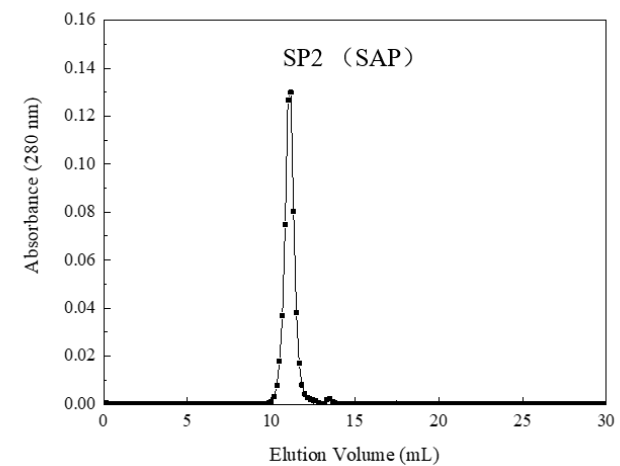

(b)

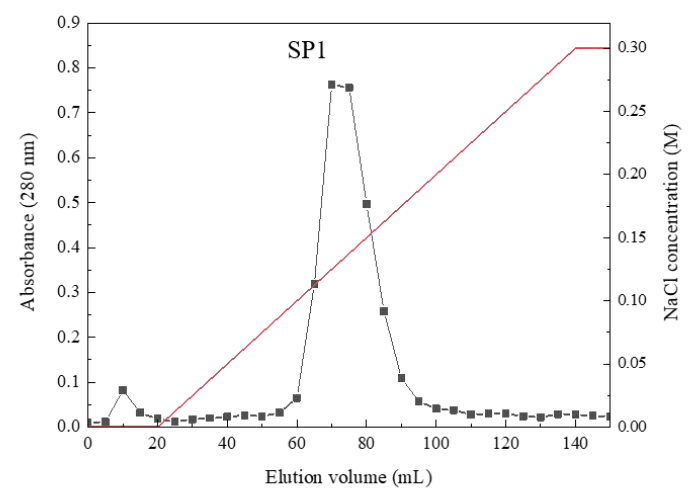

(d)

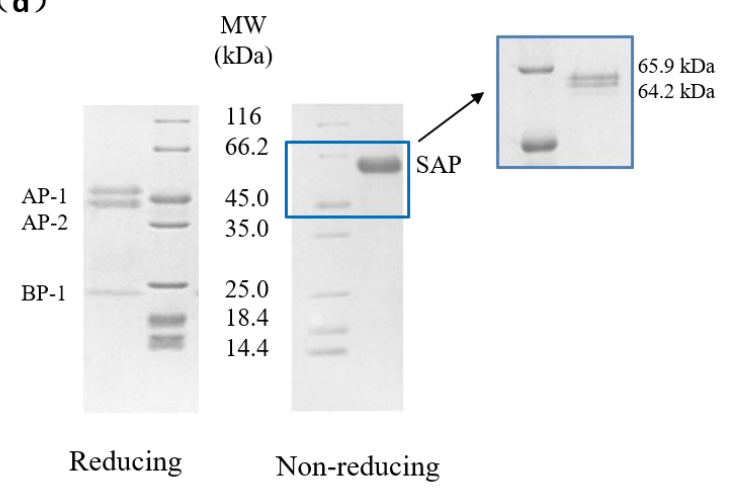

594 Figure 1. Purification and characterization of SAP. (a) SDS-PAGE of extraction.
595 Lane: 1, molecular weight marker (non-reducing); 2, heated protein solution; 3,

596 natural protein extraction. (b) Anion exchange chromatography on High Q. The

597 unloaded fraction was washed with $30 \mathrm{~mL}$ and loaded protein was eluted with $120 \mathrm{~mL}$

598 linear $\mathrm{NaCl}$ gradient $(0-0.3 \mathrm{M})$. (c) Fraction peak SP1 was collected and loaded onto a

599 TSK-GEL G6000 PW gel filtration column, eluted by phosphate buffer (pH 8.1, 20

$600 \mathrm{mM}$ ). The protein content of the eluate was monitored at $280 \mathrm{~nm}$. (d) SDS-PAGE of

601 SAP with non-reducing and reducing. An enlarged view of SAP was diluted 20 times

602 by PBS buffer. 
(a)

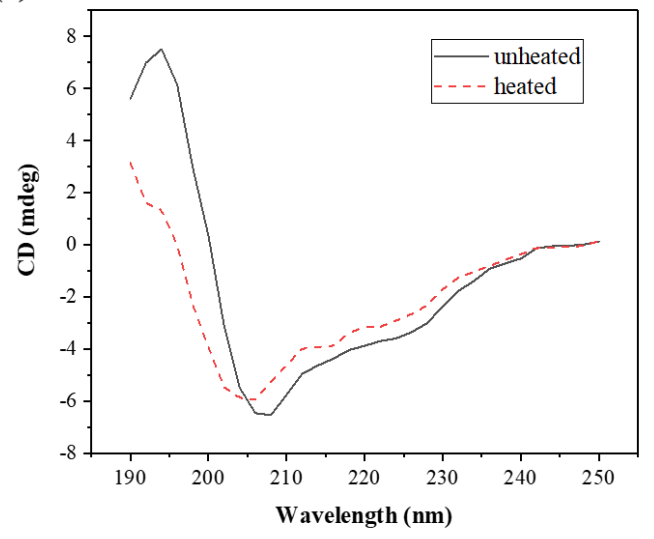

(c) (b)
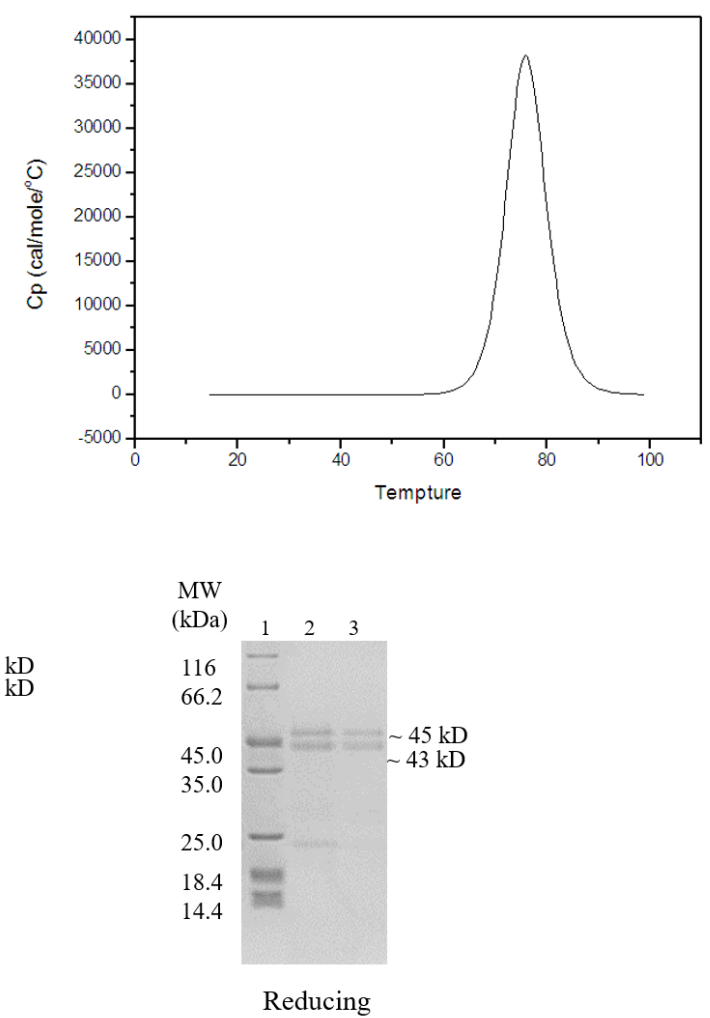

Reducing

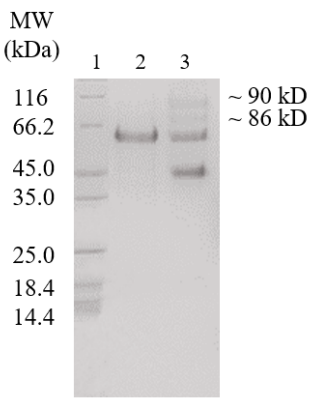

Non-reducing

605 Figure 2. Thermal analysis of SAP. (a) Circular dichroism spectra of unheated and 606 heated SAP. (b) DSC thermograms of SAP. C $C_{P}$ : heat capacity. (c) SDS-PAGE of 607 unheated and heated SAP with non-reducing and reducing. Lane: 1, molecular weight 608 marker (non-reducing); 2, unheated SAP solution; 3, heated SAP for $10 \mathrm{~min}$ at $95{ }^{\circ} \mathrm{C}$. 
(a)

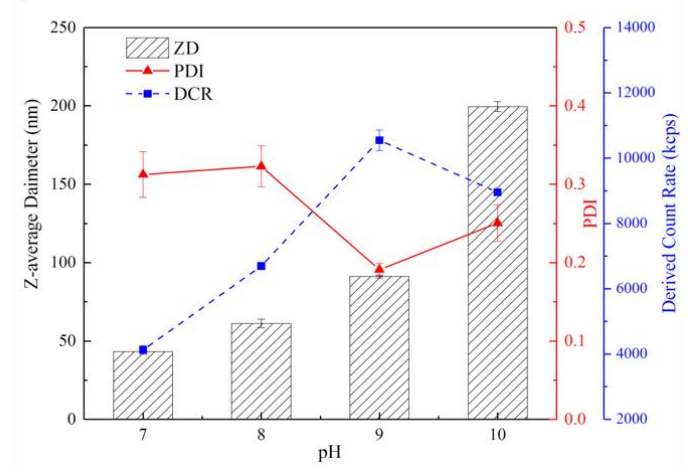

(c)

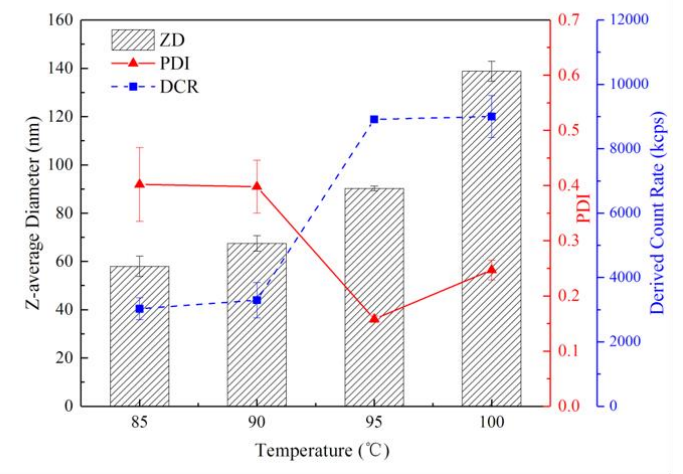

(b)

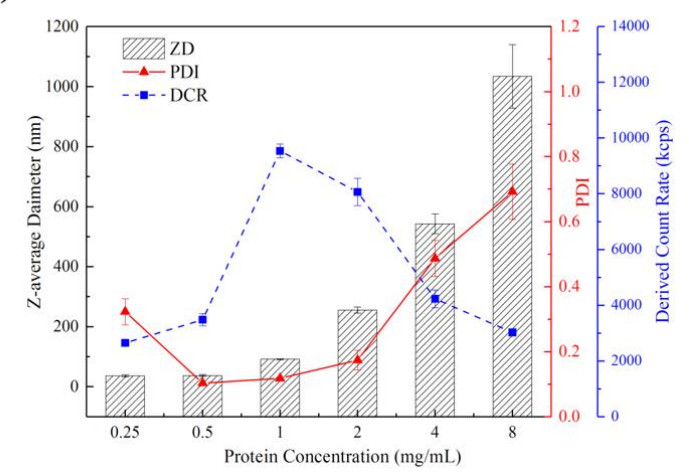

(d)

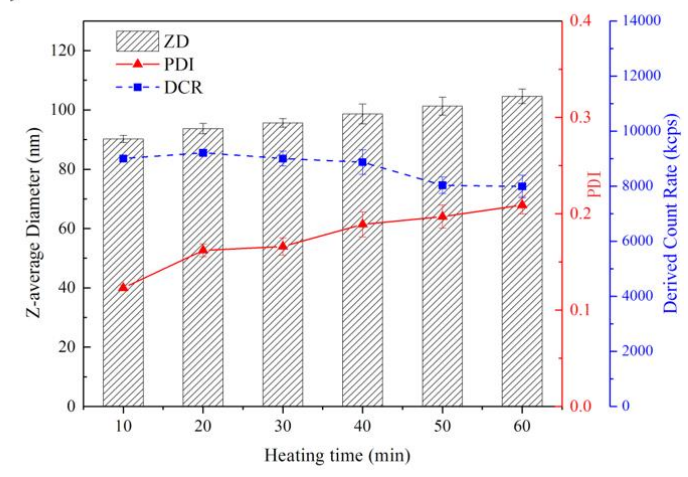

Figure 3. Influence of experimental conditions on fabrication of SAP-NPs. (a) pH. (b) 611 Figure 3. Influence of experimental conditions on fabricatior
612 Protein concentration. (c) Temperature. (d) Heating time. 
(a)

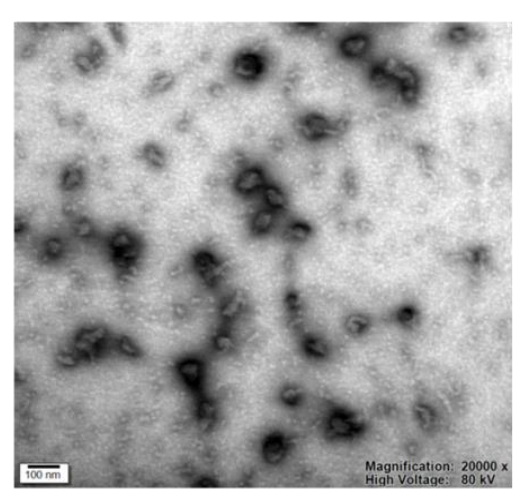

(b)

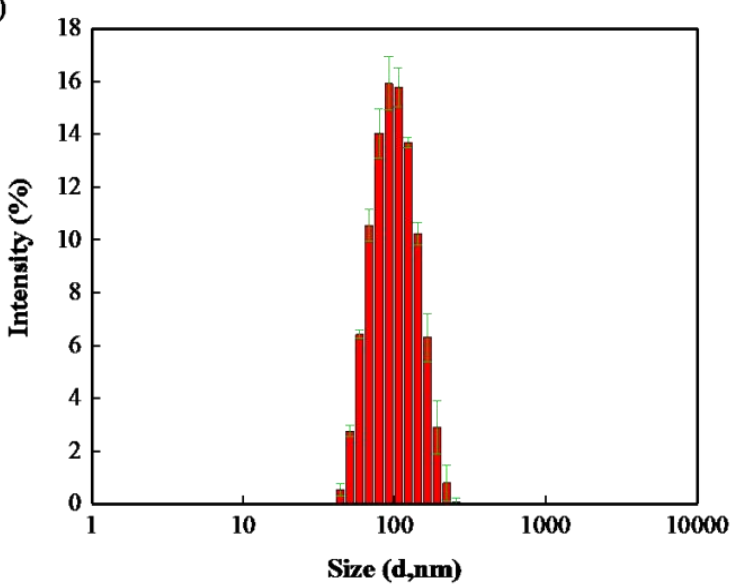

614

615 Figure 4. (a) TEM micrographs of SAP-NPs dispersions, the scale bar represents 100 $616 \mathrm{~nm}$. (b) Size distribution of SAP-NPs. The NPs prepared with $1 \mathrm{mg} / \mathrm{mL}$ SAP solution 617 ( $\mathrm{pH} 9.0)$ heated at $95{ }^{\circ} \mathrm{C}$ for $10 \mathrm{~min}$.

618 


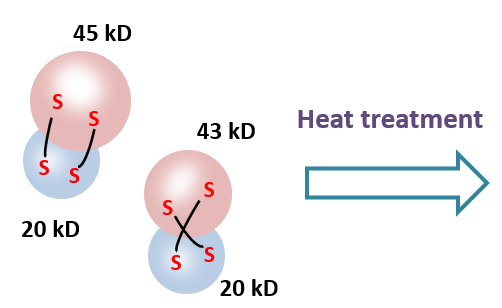

SAP (heterodimers)

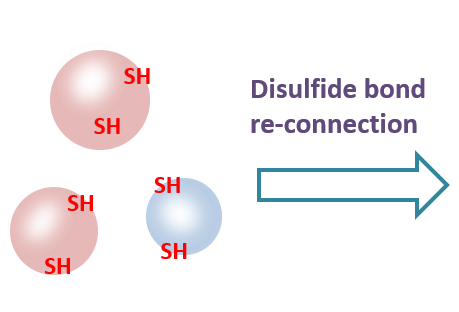

Polypeptides

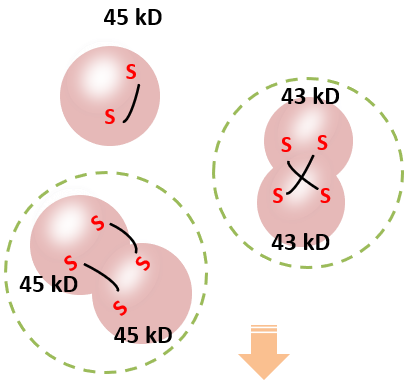

$90 \mathrm{kD}$

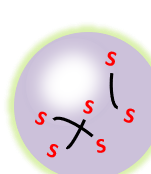

Nanoparticle

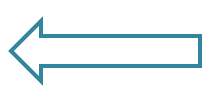

Acidic polypeptides

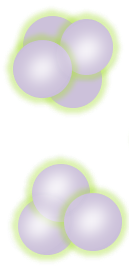

Aggregation
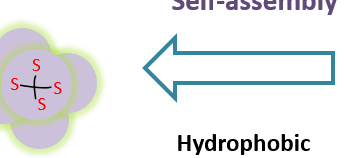

interaction
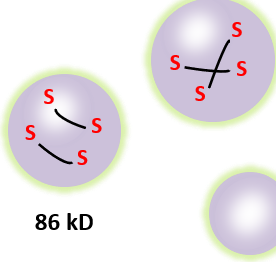

$86 \mathrm{kD}$

$45 \mathrm{kD}$

621 Figure 5. Idealized schematic representation for self-assembly of SAP-NPs. 
(a)

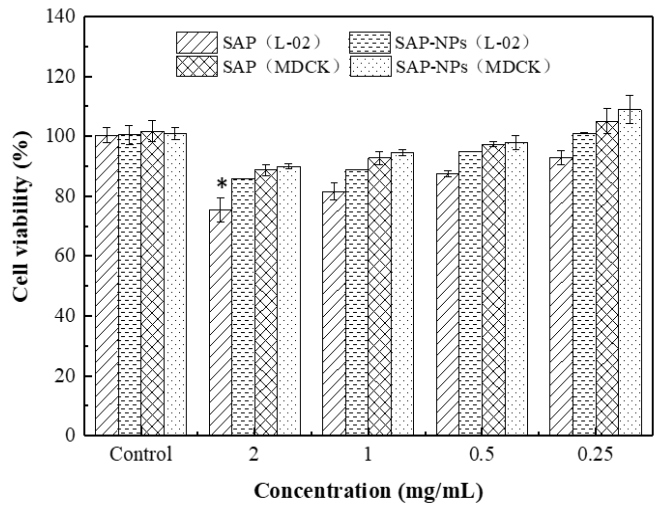

(b)

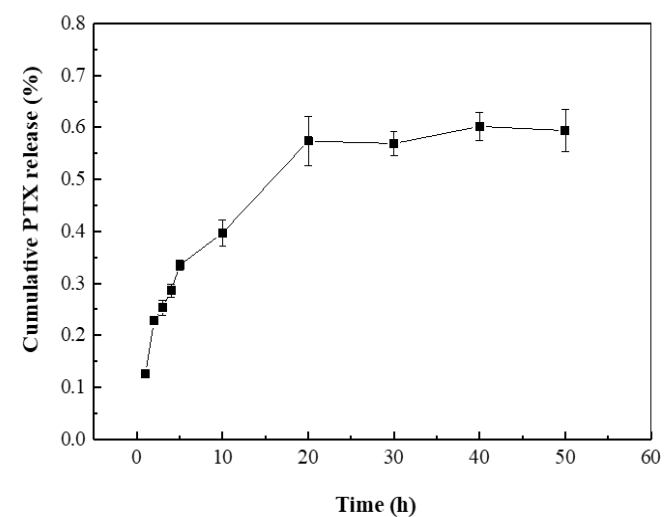

622

623 Figure 6. (a) Percentage of cell viability evaluated by MTT assay on L-02 and

624 MDCK. Control group were treated with PBS buffer. ${ }^{*} P<0.05$ compared with the 625 control group. (b) In vitro release profile of PTX from the loaded SAP-NPs.

626 